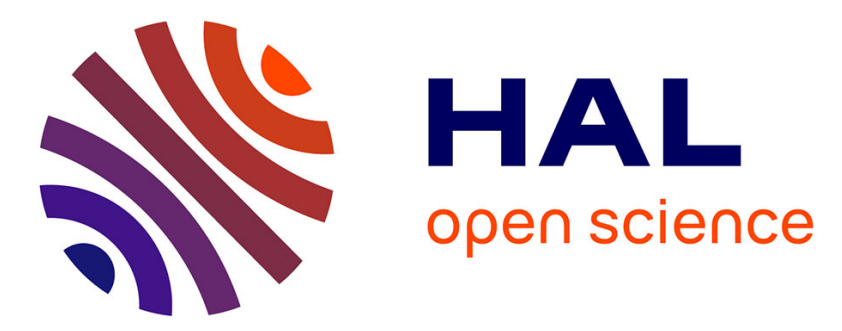

\title{
Modeling the response of a rotating eddy current sensor for the characterization of carbon fiber reinforced composites
}

\author{
H. Menana, M. Féliachi
}

\section{- To cite this version:}

H. Menana, M. Féliachi. Modeling the response of a rotating eddy current sensor for the characterization of carbon fiber reinforced composites. European Physical Journal: Applied Physics, 2010, 52 (2), 10.1051/epjap/2010079 . hal-00634368

\section{HAL Id: hal-00634368 https://hal.science/hal-00634368}

Submitted on 21 Oct 2011

HAL is a multi-disciplinary open access archive for the deposit and dissemination of scientific research documents, whether they are published or not. The documents may come from teaching and research institutions in France or abroad, or from public or private research centers.
L'archive ouverte pluridisciplinaire HAL, est destinée au dépôt et à la diffusion de documents scientifiques de niveau recherche, publiés ou non, émanant des établissements d'enseignement et de recherche français ou étrangers, des laboratoires publics ou privés. 


\title{
Modeling the response of a rotating eddy current sensor for the characterization of carbon fiber reinforced composites
}

\author{
Hocine Menana, Mouloud Féliachi \\ Université de Nantes, IREENA-IUT, BP 406, 37 Bd de l'université, 44602 Saint Nazaire, France. \\ E-mails: hocine.menana@univ-nantes.fr , mouloud.feliachi@univ-nantes.fr \\ Tel : + $33(0) 240172636$, Fax : + $33(0) 240172618$
}

PACS. 82.20.Wt Computational modeling; simulation - 81.70.Ex Nondestructive testing: electromagnetic testing, eddy-current testing

Shortened title: Rotating eddy current sensor modeling for the characterization of CFRPs

\begin{abstract}
This work deals with the eddy current nondestructive testing of carbon fiber reinforced polymer composites (CFRPs), and the development of rapid numerical models for the simulation of the interaction between the electromagnetic field and complex structures. We show qualitatively the possibility of characterizing the CFRPs by using a rotating eddy current sensor. We make use of a numerical model which we have developed in a previous work for eddy current computation in CFRPs. This model is completed in this work to account for the impedance variation of the rotating eddy current sensor, used to determine the anisotropy factor and the fiber orientation in each ply of a layered CFRP plate.
\end{abstract}

\section{Introduction}

Several experimental works have highlighted the possibility of characterizing defects in CFRPs by using the eddy current nondestructive testing technique [1]-[2]. In this work which consists in modeling and simulations, we show qualitatively the possibility of characterizing the physical properties of layered CFRPs by using a rotating eddy current sensor.

Modeling the electromagnetic field in layered CFRPs is a challenging problem due to their multi scale dimensions and their high anisotropy, associated to complex capacitive couplings due to the heterogeneity of their structures. The current calculation tools do not allow the modeling of the CFRPs on the scale of their structure; global anisotropic properties are thus assigned to them by using the homogenization techniques [3].

Semi analytical models based on the dyadic Green's functions have been proposed for the electromagnetic field modeling in anisotropic layered media [4]-[5]; these models are however limited to simple geometries. In this work, we make use of a numerical model which we have developed in a previous work for eddy current computation in CFRPs [6]. It is based on the T- $\varphi$ formulation [7], where only the parts of the system carrying a source or an induced current are discretized; the inductor motion and the multiscale dimensions of the layered CFRPs are thus easily treated. This model is completed to account for the impedance variation of a rotating eddy current sensor, used to determine the anisotropy factor and the fiber orientation in each ply of a layered CFRP plate.

\section{The modeled system}

The modeled system is described in figure 1. It consists of a rectangular air cored coil of length $l$ and width $w$, positioned at a distance $h$ above a multilayered CFRP plate of surface $L \times W$ and thickness $e$. The coil is excited with a sinusoidal current source, and rotates around an axis perpendicular to the surface of the plate (figure 1).

The structure of the considered CFRP is described in figure 2. These materials are made of several unidirectional plies of about $125 \mu \mathrm{m}$ thickness, stacked with different fiber orientations. Each unidirectional ply is constituted of carbon fibers embedded in an electrically non conductive matrix. In each ply, the electrical conductivity varies between $5 \times 10^{3}$ and $5 \times 10^{4} \mathrm{~S} / \mathrm{m}$ in the direction of the fibers, and between 10 and $10^{2} \mathrm{~S} / \mathrm{m}$ in the transverse direction, depending on the type and the volume fraction of the fibers [8], [9]-[10]. When the plies are assembled, contacts between the fibers of adjacent plies give rise to a cross ply conductivity which is of lower value, being typically half the value of the transverse conductivity [8].

The homogenized conductivity tensor of a CFRP plate is given by (1), involving the longitudinal and transversal conductivities $\left(\sigma_{L}, \sigma_{T}\right)$ of the plies, the orientation $(\theta)$ of each ply, and the cross ply conductivity $\left(\sigma_{c p}\right)[6,8]$. 


$$
\overline{\bar{\sigma}}=\left(\begin{array}{ccc}
\sigma_{L} \cos ^{2}(\theta)+\sigma_{T} \sin ^{2}(\theta) & \frac{\sigma_{L}-\sigma_{T}}{2} \sin (2 \theta) & 0 \\
\frac{\sigma_{L}-\sigma_{T}}{2} \sin (2 \theta) & \sigma_{L} \sin ^{2}(\theta)+\sigma_{T} \cos ^{2}(\theta) & 0 \\
0 & 0 & \sigma_{c p}
\end{array}\right)
$$

\section{The model equations}

In the following, $\Omega_{\mathrm{S}}$ and $\Omega_{\mathrm{C}}$ denote respectively the volumes of the source (coil) and the CFRP plate regions. The latter is delimited by the frontier $\Gamma$. The source region is the support of a current density $\boldsymbol{J}_{\boldsymbol{s}}$ with a time harmonic variation. The electromagnetic problem is formulated in terms of the electric vector potential $\boldsymbol{T}$ and the scalar magnetic potential $\varphi$, governed by the equations (2)-(3) in $\Omega_{\mathrm{C}}$, involving the conductivity tensor $\overline{\bar{\sigma}}$ of the CFRP plate, the free space permeability $\mu_{0}$ and the angular frequency $\omega[6]$.

$$
\begin{array}{r}
\nabla \times \overline{\bar{\sigma}}^{-1} \nabla \times \mathbf{T}+j \omega \mu_{0}(\mathbf{T}-\nabla \varphi)=-j \omega \mu_{0} \mathbf{H}_{\mathrm{s}} \\
\nabla \cdot\left(\mathbf{H}_{\mathrm{s}}+\mathbf{T}-\nabla \varphi\right)=0
\end{array}
$$

The eddy currents density $\boldsymbol{J}$ in $\Omega_{\mathrm{C}}$ is given by

$$
\mathbf{J}=\nabla \times \mathbf{T} .
$$

To cancel the normal component of the current density at the frontiers of $\Omega_{\mathrm{C}}$, the following boundary condition has to be imposed

$$
\mathbf{n} \times \mathbf{T}=\mathbf{0} / \Gamma .
$$

The source term $\boldsymbol{H}_{s}$ in (2) is calculated by the Biot and Savart formulae given by (6), in which $\left\|\boldsymbol{r}-\boldsymbol{r}^{\prime}\right\|$ is the distance between a source point in $\Omega_{\mathrm{S}}$ and a point in $\Omega_{\mathrm{C}}$ where the magnetic field $\boldsymbol{H}_{s}$ is evaluated.

$$
\mathbf{H}_{\mathbf{S}}(\mathbf{r})=\frac{1}{4 \pi} \int_{\Omega_{S}} \frac{\mathbf{J}_{\mathbf{S}}\left(\mathbf{r}^{\prime}\right) \times\left(\mathbf{r}-\mathbf{r}^{\prime}\right)}{\left\|\mathbf{r}-\mathbf{r}^{\prime}\right\|^{3}} d \Omega
$$

Only the active parts of the system are discretized; the equations (2) (3) and (4) are discretized by using the finite difference method in $\Omega_{\mathrm{C}}$. The source term $\boldsymbol{H}_{s}$ is evaluated at each node of the finite difference mesh by mean of (6). The source region $\Omega_{\mathrm{S}}$ is discretized into $N s$ elementary volumes; the current source density $\boldsymbol{J}_{s}$ is defined at the center of each elementary volume. The discrete form of the integral (6) is given as follows [6]

$$
\overline{\mathbf{H}}_{\mathrm{s}}=\overline{\overline{\mathrm{M}}}_{s} \overline{\mathbf{J}}_{\mathrm{s}} .
$$

Taking account of (7), the discrete forms of (2) (3) and (4) are given as follows [6]

$$
\begin{array}{r}
\left(\overline{\overline{\mathrm{C}}} \overline{\overline{\mathrm{R}}} \overline{\overline{\mathrm{C}}}+j \omega \mu_{0} \overline{\overline{\mathrm{I}}}\right) \overline{\mathbf{T}}-j \omega \mu_{0} \overline{\overline{\mathrm{G}}} \bar{\varphi}=-j \omega \mu_{0} \overline{\overline{\mathrm{M}}}_{\mathrm{s}} \overline{\mathbf{J}}_{\mathrm{s}}, \\
\overline{\overline{\mathrm{D}}}\left(\overline{\overline{\mathrm{M}}}_{s} \overline{\mathbf{J}}_{\mathrm{s}}+\overline{\mathbf{T}}-\overline{\overline{\mathrm{G}}} \bar{\varphi}\right)=0, \\
\overline{\mathbf{J}}=\overline{\overline{\mathrm{C}}} \overline{\mathbf{T}} .
\end{array}
$$

Details about the development of the matrices involved in the equations (7) to (10), as well as a validation of these equations are given in [6]. 
The impedance variation $(\Delta Z)$ of the coil, due to the eddy currents flowing in the CFRP plate, is calculated by using equation (11) [4], where $I_{s}$ is the source current, and $\boldsymbol{E}_{\boldsymbol{i}}$ the electric field scattered by the CFRP plate, and calculated using the Biot and Savart formulae (12) once the eddy currents density $\boldsymbol{J}$ in $\Omega_{\mathrm{C}}$ is obtained.

$$
\begin{array}{r}
\Delta Z=\frac{-1}{I_{s}^{2}} \int_{\Omega_{S}} \mathbf{E}_{i} \cdot \mathbf{J}_{\mathbf{s}} d \Omega \\
\mathbf{E}_{i}(\mathbf{r})=\frac{-j \omega \mu_{0}}{4 \pi} \int_{\Omega_{C}} \frac{\mathbf{J}\left(\mathbf{r}^{\prime}\right)}{\left\|\mathbf{r}-\mathbf{r}^{\prime}\right\|} d \Omega, \quad\left(\mathbf{r}^{\prime} \in \Omega_{C}\right)
\end{array}
$$

Introducing (12) in (11), we obtain

$$
\Delta Z=\frac{j \omega \mu_{0}}{4 \pi I_{s}^{2}} \int_{\Omega_{S}} \int_{\Omega_{C}} \frac{\mathbf{J}_{s}(\mathbf{r}) . \mathbf{J}\left(\mathbf{r}^{\prime}\right)}{\left\|\mathbf{r}-\mathbf{r}^{\prime}\right\|} d \Omega_{S} d \Omega_{C}\left(\begin{array}{c}
\mathbf{r} \in \Omega_{S} \\
\mathbf{r}^{\prime} \in \Omega_{C}
\end{array}\right)
$$

The discrete form of (13) is given by (14), where $v s_{n}$ and $v c_{m}$ are elementary volumes of the source and the CFRP plate regions respectively, and $\left\|\mathbf{r}_{n}-\mathbf{r}_{m}\right\|$ is the distance between them as shown in figure 3. $N c$ is the number of the elementary volumes of the CFRP plate. Since the plies are very thin, the current density is assumed to be constant along the section of each ply; each ply is then represented by only one layer of finite difference mesh nodes. Each elementary volume $v c_{m}$ results from the surface defined by four adjacent finite difference mesh nodes $(i, j, k ; i, j+1, k$; $i+1, j, k ; i+1, j+1, k)$ multiplied by the thickness $(\delta p)$ of the ply number $k$. The current density $\boldsymbol{J}_{\boldsymbol{m}}$ in the element $v c_{m}$ is obtained by averaging the contribution of the four finite difference mesh nodes.

$$
\begin{array}{r}
\Delta Z=\frac{j \omega \mu_{0}}{4 \pi I_{s}^{2}} \sum_{n=1}^{N s} \sum_{m=1}^{N c} \frac{v s_{n} v c_{m}}{\left\|\mathbf{r}_{n}-\mathbf{r}_{m}\right\|} \mathbf{J}_{s n} . \mathbf{J}_{m} \\
\mathbf{J}_{m}=\frac{1}{4}\left(\mathbf{J}_{i, j, k}+\mathbf{J}_{i+1, j, k}+\mathbf{J}_{i, j+1, k}+\mathbf{J}_{i+1, j+1, k}\right) \\
v c_{m}=\delta p\left\|\mathbf{r}_{i+1, j, k}-\mathbf{r}_{i, j, k}\right\| \cdot\left\|\mathbf{r}_{i, j+1, k}-\mathbf{r}_{i, j, k}\right\| \\
\mathbf{r}_{m}=\frac{1}{4}\left(\mathbf{r}_{i, j, k}+\mathbf{r}_{i+1, j, k}+\mathbf{r}_{i, j+1, k}+\mathbf{r}_{i+1, j+1, k}\right)
\end{array}
$$

The equation (14) can be written in a matrix form as follows

$$
\Delta \mathbf{Z}=\overline{\mathbf{J}}^{\mathrm{T}} \overline{\overline{\mathbf{M}}} \overline{\mathbf{J}}_{\mathbf{s}},
$$

where

$$
\overline{\overline{\mathrm{M}}}=\left[\begin{array}{ccc}
\overline{\overline{\mathrm{M}}}_{s c} & 0 & 0 \\
0 & \overline{\overline{\mathrm{M}}}_{s c} & 0 \\
0 & 0 & \overline{\overline{\mathrm{M}}}_{s c}
\end{array}\right], \overline{\mathbf{J}}_{\mathrm{s}}=\left[\begin{array}{l}
\left\{J_{s}\right\}_{x} \\
\left\{J_{s}\right\}_{y} \\
\left\{J_{s}\right\}_{z}
\end{array}\right], \overline{\mathbf{J}}=\left[\begin{array}{l}
\{J\}_{x} \\
\{J\}_{y} \\
\{J\}_{z}
\end{array}\right] .
$$

The matrix $\overline{\overline{\mathrm{M}}}_{s c}$ is of dimension $(N s \times N c)$; its elements are calculated as follows 


\section{Numerical examples}

$$
M_{s c}(n, m)=\frac{j \omega \mu_{0}}{4 \pi I_{s}^{2}} \frac{v s_{n} v c_{m}}{\left\|\mathbf{r}_{n}-\mathbf{r}_{m}\right\|}
$$

In these numerical examples, we consider the system presented in figure 1. We show qualitatively the influences of the anisotropy factor, the fibers orientations $(\theta)$ in the CFRP plate and the coil design on the impedance variation of the latter. The numerical values of the modeled systems parameters are given in table1. Two CFRP plates are considered; the first one is constituted of one unidirectional ply of $125 \mu \mathrm{m}$ thickness and the second one is constituted of four unidirectional plies of $125 \mu \mathrm{m}$ thickness oriented in the directions $\left(0^{\circ}, 45^{\circ}, 90^{\circ},-45^{\circ}\right)$. The direction of the fibers of the upper ply is taken as reference $\left(\theta=0^{\circ}\right)$. The rectangular coil, of $10 \mathrm{~mm}$ length, rotates above the CFRP plate with an angular step $\left(\Delta \alpha=3^{\circ}\right)$; its impedance variation is recalculated at each position $(\alpha)$. First, we studied the influences of the plate anisotropy and the coil width on its impedance variation. We considered one unidirectional CFRP ply. Figure 4 represents the real and imaginary parts of the normalized impedance variation according to the coil rotation above the ply, for different values of the coil width $(w)$. The impedance variation $(\Delta Z)$ is in the form of lobes oriented in the direction of the fibers $\left(\theta=0^{\circ}\right)$. We notice that increasing the coil width leads to a significant increase of $\Delta Z$ at $(\alpha=\theta \pm \pi)$ (coil oriented in the fibers direction), and a modest increase of $\Delta Z$ at $(\alpha=\theta \pm \pi / 2)$ (coil oriented in the direction transverse to the fibers). The imaginary part is about only $2 \%$ of the total impedance variation. Figure 5 represents the real part of the normalized impedance variation according to the coil rotation, for different values of the transversal conductivity $\left(\sigma_{T}\right)$ and a fixed value of the longitudinal conductivity $\left(\sigma_{L}\right)$. We notice that increasing the transversal conductivity leads to a significant and non proportional increase of $\Delta Z$ at the position $(\alpha=\theta \pm \pi)$, and a modest proportional increase of $\Delta Z$ at the position $(\alpha=\theta \pm \pi / 2)$. Figure 6 represents the real part of the normalized impedance variation according to the coil rotation, for different values of the longitudinal conductivity and a fixed value of the transversal conductivity. We notice that increasing the longitudinal conductivity leads to a significant and non proportional increase of $\Delta Z$ at $(\alpha=\theta \pm \pi)$, and a negligible increase of $\Delta Z$ at $(\alpha=\theta \pm \pi / 2)$. Figures 5 and 6 can be used to calibrate the sensor for the inverse problem which leads to the determination of the longitudinal and transversal conductivities from measurements of $\Delta Z$ at $(\alpha=\theta \pm \pi)$ and $(\alpha=\theta \pm \pi / 2)$.

In the second step, we studied the influence of the coil width on the determination of the fiber orientations in a multi-layer CFRP plate. Figure 7 shows the normalized impedance variation according to the coil rotation above a CFRP plate constituted of four plies oriented in the directions $\left(0^{\circ}, 45^{\circ}, 90^{\circ},-45^{\circ}\right)$, for different widths $(w)$ of the coil. When the coil width is too large $(w=2 \mathrm{~mm})$, the influence of the fiber orientation in the lower plies on the impedance variation is hidden by the influence of the upper plies. On the other hand, a small width $(w=1 \mathrm{~mm})$ leads to a weak interaction between the coil and the lower plies. The coil width must then satisfy a compromise between the sensitivity and the distinguishability. Figure 8 shows the eddy currents repartition in the four plies plate when the rectangular coil is oriented in the direction of the fibers of the first ply $\left(\alpha=\theta=0^{\circ}\right)$. The effect of the anisotropy on the eddy current repartition in the plies is noticeable; the eddy currents are stretched in the direction of the high conductivity.

Finally, to give an idea about the computing time, the latter is of about $30 \mathrm{~min}$ for 120 positions of the coil on the four plies plate discretized into $(50 \times 50 \times 4)$ nodes. A PC of $3.4 \mathrm{GHz}$ processor is used. The matrices in equations (7) to (18) are calculated only once; this makes the calculation fast.

\section{Conclusion}

We have shown the possibility of characterizing CFRPs by using a rotating eddy current sensor of a rectangular shape. Although the results in the treated examples are only qualitative, interesting phenomena have been observed, giving rise to new ideas which will be developed in future works. In the short run, we envisage the development of an inverse model associated to the rotating eddy current sensor for the electrical conductivity characterization in CFRPs, and applications to defects characterization such as delaminations and fiber breakings. An experimental validation is also necessary to determine the frequency limit of validity of the model equations. In the long run, we project to take account of the capacitive effects in the modelling. 


\section{Acknowledgments}

Work supported by Nantes Métropole.

\section{References}

1. Gerhard Mook, Rolf Lange, Ole Koeser, Composites Science and Technology 61, 865 (2001)

2. Xavier E. Gros, Materials\&Design 16, 167 (1995)

3. D. Trichet, E. Chauveau, and Javad Fouladgar, IEEE Trans. Magn. 36, 1193 (2000)

4. John R. Bowler, L. David Sabbagh, Harold A. Sabbagh, IEEE Trans. Magn. 25, 2650 (1989)

5. H.-Y. D. Yang. IEEE Trans. Antennas \& Propagat. 45, 520 (1997)

6. Hocine Menana, Mouloud Féliachi, IEEE Trans. Magn. 45, 1008 (2009)

7. F. Bouillault, Z. Ren and A. Razek, IEEE Trans. Magn. 26, 478 (1990)

8. S. B. Pratap, and W. F. Weldon, IEEE Trans. Magn. 32, 437 (1996)

9. R. Grimberg, A. Savin, R. Steigmann, A. Bruma, in Proceedings of the $8^{\text {th }}$ International Conference of the Slovenian Society for Non-Destructive Testing, Portorož, 2005, p. 223

10. J. B. Park, T. K. Hwang, H. G. Kim and Y. D. Doh, Smart Mater. Struct. 16, 57 (2007)

\section{Figures and tables captions}

Fig. 1. The modeled system

Fig. 2. Structure of the considered CFRPs

Fig. 3. Elementary volumes of the source and the CFRP plate regions

Fig. 4. The real and imaginary parts of the normalized impedance variation according to the coil rotation above a CFRP ply, for different values of the coil width, $\left(\sigma_{L}=10^{4} \mathrm{~S} / \mathrm{m}, \sigma_{T}=10^{2} \mathrm{~S} / \mathrm{m}\right)$

Fig. 5. The real part of the normalized impedance variation according to the coil rotation above above a CFRP ply, for different values of the transversal conductivity, $\left(w=1 \mathrm{~mm}, \sigma_{L}=10^{4} \mathrm{~S} / \mathrm{m}\right)$

Fig. 6. The real part of the normalized impedance variation according to the coil rotation above a CFRP ply, for different values of the longitudinal conductivity, $\left(w=1 \mathrm{~mm}, \sigma_{T}=10^{2} \mathrm{~S} / \mathrm{m}\right)$

Fig. 7. The normalized impedance variation according to the coil rotation a CFRP plate constituted of four plies $\left(0^{\circ}, 45^{\circ}, 90^{\circ},-45^{\circ}\right)$, for two widths of the rectangular coil $\left(\sigma_{L}=10^{4} \mathrm{~S} / \mathrm{m}, \sigma_{T}=10^{2} \mathrm{~S} / \mathrm{m}\right)$

Fig. 8. Eddy currents repartition in the four plies plate when the rectangular coil is oriented in the direction of the fibers of the first ply $\left(\theta=0^{\circ}\right)$.

Table 1. The numerical values of the modeled system parameters 


\section{Figures}

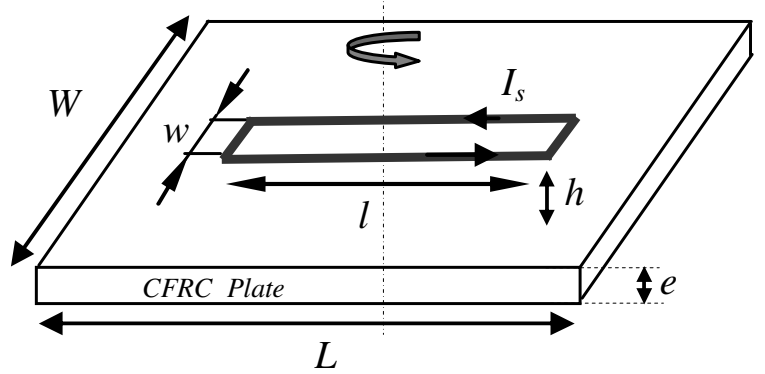

Fig. 1

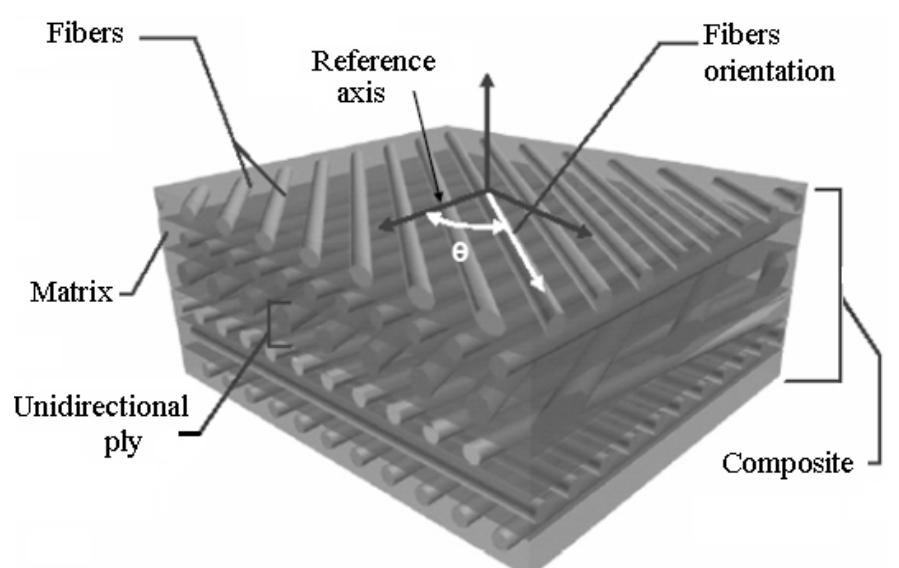

Fig. 2

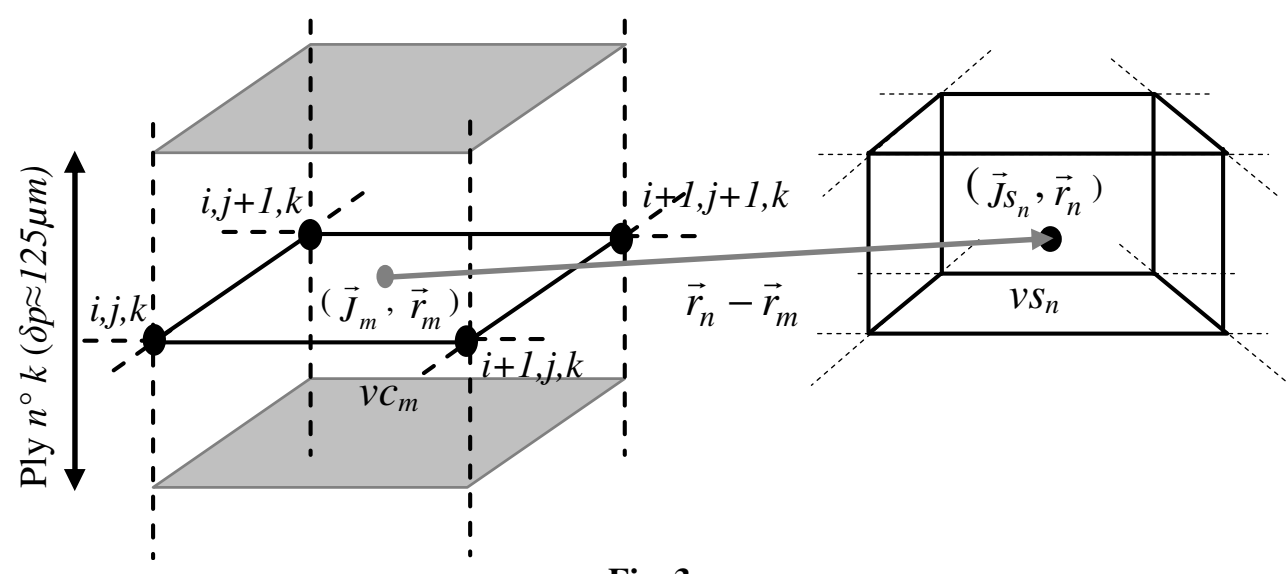

Fig. 3 


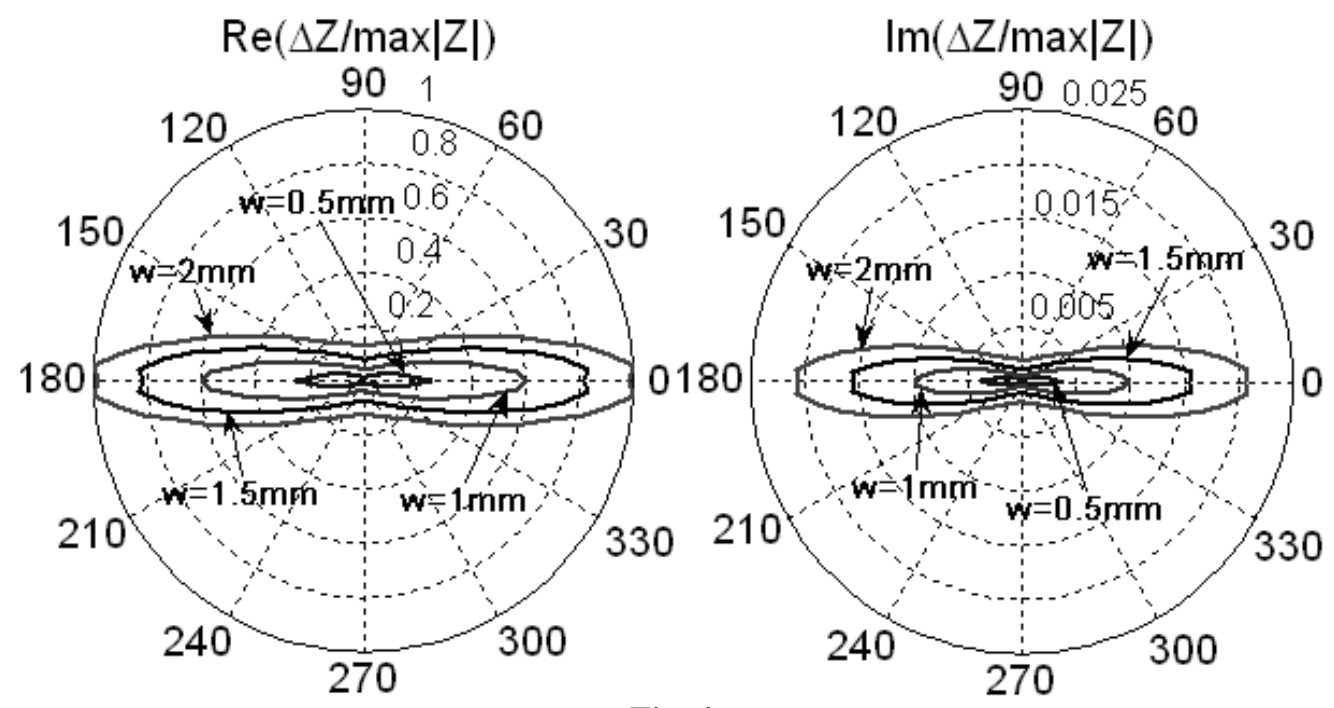

Fig. 4

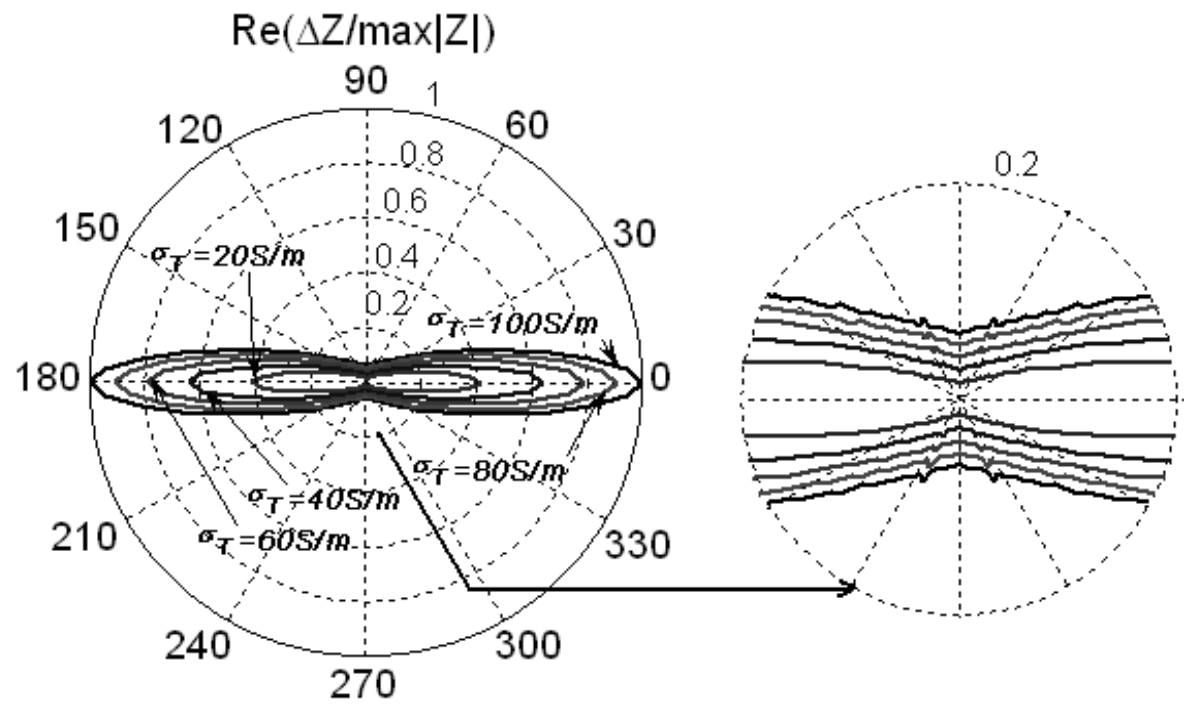

Fig. 5

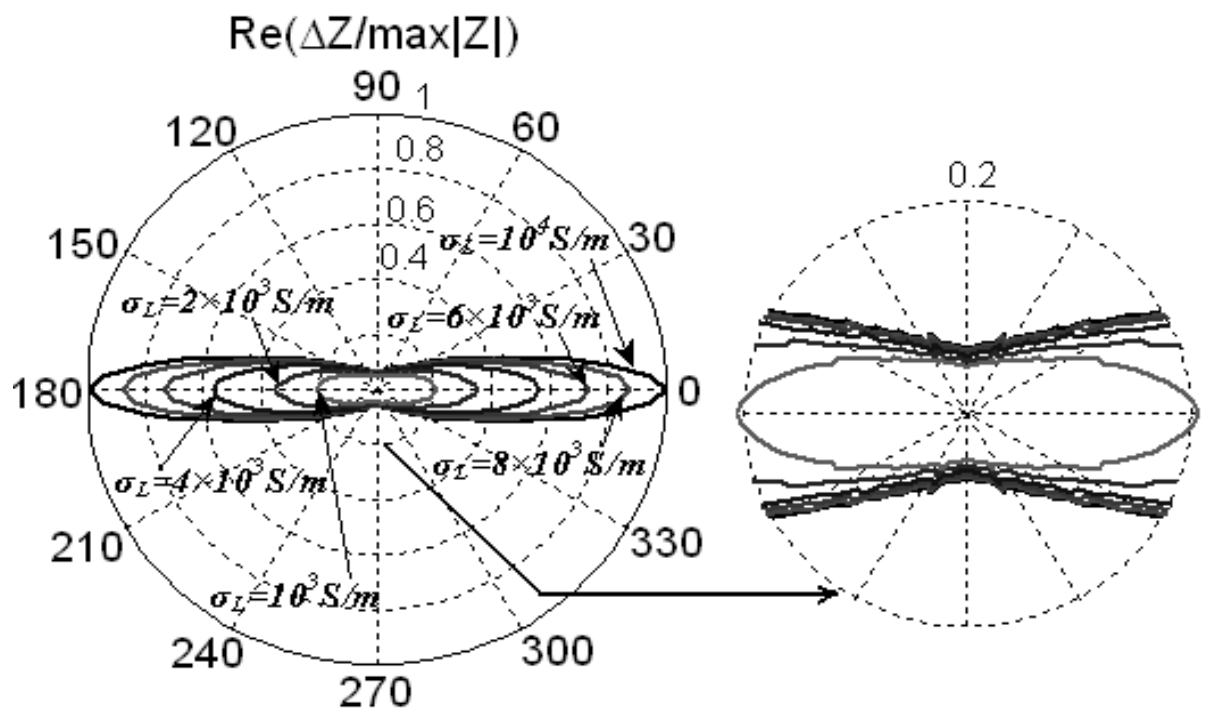

Fig. 6 

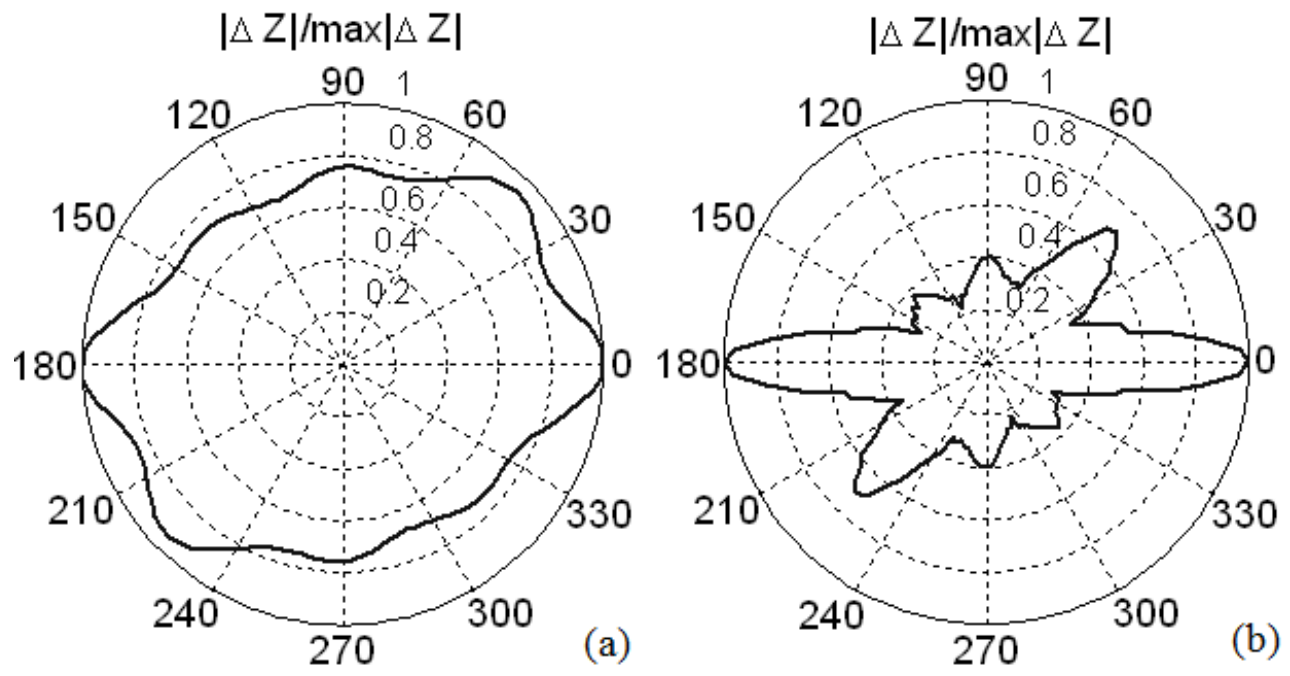

Fig. 7
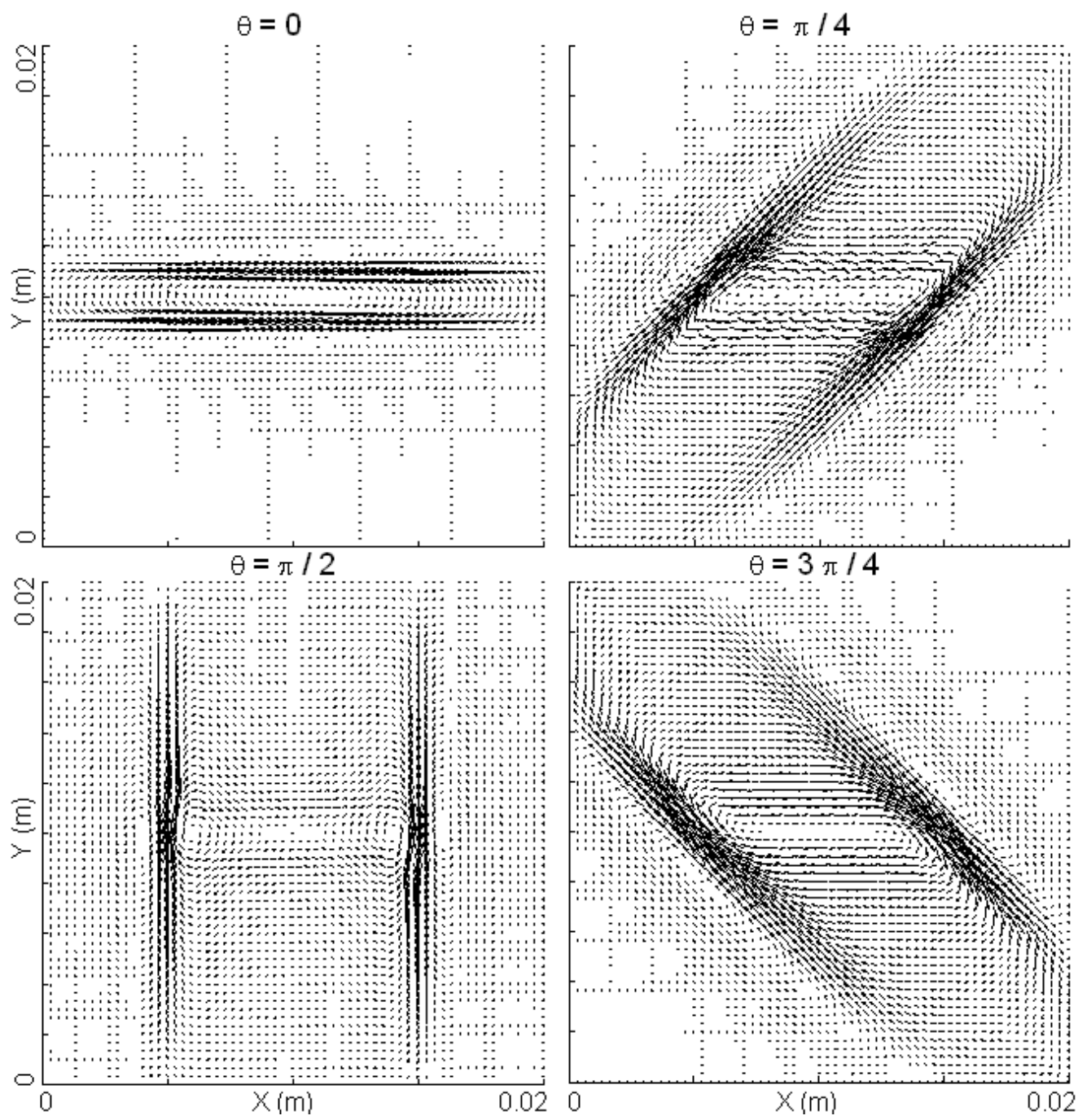

Fig. 8 
Tables

Table 1

\begin{tabular}{|c|c|c|}
\hline \multirow{2}{*}{$\begin{array}{l}\text { Parameters } \\
\text { CFRP plate }\end{array}$} & \multicolumn{2}{|c|}{ Values } \\
\hline & One ply plate & Four plies plate \\
\hline Number of plies & 1 & 4 \\
\hline Fibers orientations $(\theta)$ & $0^{\circ}$ & $0^{\circ}, 45^{\circ}, 90^{\circ},-45^{\circ}$ \\
\hline Conductivities $\left(\sigma_{L}, \sigma_{T}, \sigma_{c p}\right)$ & (variable, variable, 0$) \mathrm{S} / \mathrm{m}$ & (variable, variable, 0$) \mathrm{S} / \mathrm{m}$ \\
\hline Thickness $(e)$ & $0.125 \mathrm{~mm}$ & $0.5 \mathrm{~mm}$ \\
\hline Surface $(L \times W)$ & $(30 \times 30) \mathrm{mm}^{2}$ & $(30 \times 30) \mathrm{mm}^{2}$ \\
\hline \multicolumn{3}{|l|}{ Coil } \\
\hline Number of turns & 1 & \\
\hline length $(l)$ & $10 \mathrm{~mm}$ & \\
\hline Width $(w)$ & $1 \mathrm{~mm} / 2 \mathrm{~mm}$ & \\
\hline Intensity $(I s)$, Frequency & $0.1 \mathrm{~A}, 1 \mathrm{MHz}$ & \\
\hline Lift off $(h)$ & $0.1 \mathrm{~mm}$ & \\
\hline Angular step of rotation $(\Delta \alpha)$ & $3^{\circ}$ & \\
\hline
\end{tabular}

